\title{
A Study of Problem Behaviors in 10- to 15-Year-Old Biologically Related and Unrelated International Adoptees
}

\author{
Edwin J. C. G. van den Oord, ${ }^{1-3}$ Dorret I. Boomsma, ${ }^{2}$ and Frank C. Verhulst ${ }^{1}$
}

Received 15 Feb. 1993-Final 10 Mar. 1994

Genetic and environmental influences on problem behaviors were studied in a sample of international adoptees. Parental ratings of childrens' problem behaviors were obtained with the Child Behavior Checklist (CBCL). The sample (mean age, 12.4 years) comprised a group of biological siblings (111 pairs), a group of nonbiological siblings (221 pairs), and a group of singletons (94). Nonshared environmental influences were most important for problem behaviors studied in this paper. Genetic influences were substantial for Externalizing behaviors but unimportant for Internalizing behaviors. For the CBCL total problem score, Attention Problems, and Externalizing behaviors, the results of the present study were in agreement with findings from twin studies. The lack of genetic influences on Internalizing behaviors contrasts with results from twin studies. For the total problem score, the Externalizing grouping, Delinquent Behavior, and Aggressive Behavior, variances for singletons were significantly smaller than for siblings. Model fit indices indicated that these differences in variances are better attributed to smaller effects of factors associated with sibship size than to active influences of siblings on each other. Significant sex differences were found for 8 of the 10 scales. The larger variances for boys on the Externalizing grouping and Aggressive Behavior could be explained by genetic influences.

KEY WORDS: Child/adolescent behavior problems; Child Behavior Checklist; behavior genetics; sibling effects; sex differences.

\section{INTRODUCTION}

In both psychiatry and genetics there is an increasing interest in the study of genetic factors underlying problem behaviors in children (Rutter et al., $1990 \mathrm{a}, \mathrm{b})$. Behavioral/emotional problems in children and adolescents generally involve quantitative variations of behavior that most children display to some degree, rather than discrete categories that are either present or absent. It is likely that for these continuous variations the effects of many genes are

\footnotetext{
${ }^{1}$ Department of Child and Adolescent Psychiatry, Sophia Children's Hospital-Erasmus University, Rotterdam, The Netherlands.

2 Department of Psychonomics, Free University, Amsterdam, The Netherlands.

${ }^{3}$ To whom correspondence should be addressed at Czar Peterstraat $35 \mathrm{~s}, 1018 \mathrm{NX}$ Amsterdam, The Netherlands.
}

involved (McGuffin and Gottesman, 1985), and most genetic studies have therefore employed the meth ods of quantitative genetic theory. This approach has proven to be a powerful tool for disentangling genetic and environmental influences, and its application in the area of child psychopathology has led to a broader recognition for that children's problem behaviors genetic as well as environmental factors may be involved.

In the area of child psychopathology most of the findings are twin study inferences about genetic and environmental effects. There are, however, a number of possible limitations associated with the classical twin study. For example, twin samples show higher rates of congenital anomalies (Rutter and Redshaw, 1991), and parental expectations that 
MZ twins will develop along similar lines could spuriously inflate estimates of genetic influences. Thus, the generalization of findings to the general population may be limited, and estimates of genetic and environmental influences biased. The implication of this is that different types of samples should be employed. Although all inferences about genetic and environmental influences may suffer from limitations, they are not necessarily the same for all samples (Rutter et al., 1990a).

A second possible limitation concerns the model used for data analysis. In the classical twin study, sibling resemblance is viewed as caused by the "passive" sharing of genes and environments. A number of authors have suggested that this passive view may be too simplistic (Carey, 1986; Dunn, 1983; Eaves, 1976; Patterson, 1982). For instance, by imitating each others behaviors, siblings may become more alike. The probable importance of these sibling interactions have been noted in the area of juvenile delinquency (Rowe, 1983; Shields, 1977), and evidence for such influences in adult delinquency (Carey, 1992) and boys' Externalizing behaviors has recently been found (Neale and Cardon, 1992). Furthermore, Rutter et al. (1970, pp. 222-223) reported associations between sibship size and a variety of problem behaviors in children. These associations do not necessarily refer to active influences from siblings on each other. It also seems reasonable to suppose that as the number of children in the family increases, there is a decrease in the amount of time parents spend with any child (Patterson, 1982, p. 22), or that children benefit from offering and receiving comfort from siblings (Dunn and McGuire, 1992). Sibship size could therefore simply be a harmful or beneficial factor by itself. In either case, in a genetic design it is important to examine whether siblings interact in an active way or if sibship size represents an aspect of a shared environment from which children are passive recipients. With an appropriate or too simplistic model, erroneous conclusions about the relative importance of genetic and environmental influences are obtained.

The sample in the present study consisted of international adoptees and comprised groups of biologically related and unrelated sibling pairs. These groups enabled us to study genetic and environmental influences on problem behaviors. A group of adopted biological siblings is rather unique. In most sibling adoption designs, the difference in the resemblance of adopted children and biological children of adoptive parents versus the resemblance of the nonadopted biological siblings is used to study genetic influences. Thus, adopted children are usually compared with controls who are raised by their biological parents, while in our study both groups are raised by adoptive parents.

For a number of childhood behavior problems such as anxiety, depression, or aggressive behaviors no adoption study has been reported yet. The adoption sample in the present study therefore provided an opportunity for a comparison with twin study inferences about genetic and environmental effects on problem behaviors in children. If the same results are obtained, conclusions are more likely to be valid.

In addition to the groups of sibling pairs, there was a group of adoptees who grew up as singletons. Such a group of singletons can be contrasted with groups of siblings to study the influence of multiple children within one family.

\section{METHOD}

\section{Assessment Instrument}

Parental ratings of children's problem behaviors were obtained with the Child Behavior Checklist (CBCL; Achenbach, 1991). The CBCL consists of 120 items, which describe a broad range of problems of concern to parents and clinicians. Parents are requested to circle a 0 if the problem is not true of a child, a 1 if the item is somewhat or sometimes true, and a 2 if it is very true or often true.

The CBCL is scored on eight syndromes, which were constructed by identifying similar syndromes present in the separate principal-components solutions obtained for different types of informants (parents, teachers, and adolescents themselves), girls and boys, and age groups 4-11 and 12-18 (Achenbach, 1991, pp. 6-7). These eight so-called crossinformant syndrome constructs offer a number of advantages in comparison to earlier reported syndromes. Not only is the coordination of data from different informants facilitated, but also sex and age differences are studied more easily because the same constructs apply to each informant, sex, and age group.

A confirmatory factory analysis was used to study the applicability of the eight constructs in the sample of international adoptees (van den Oord, 1993). Results supported the validity of the constructs. However, in the sample of international 
adoptees a number of items had very low variances, were not indicators of just one construct, or did not improve the reliability of the scale. Therefore, scales somewhat different from the ones reported by Achenbach (1991) were used in the present study for Withdrawn (items 17, 65, 69, 80, 102, 111), Somatic Complaints (items 4, 56b, 56c, 56f), Anxious/Depressed (items 12, 14, 31, 33, 35, 45, 50, 103, 112), Social Problems (items 25, 38, 48), Attention Problems (items 1, 8, 10,13, 62), Delinquent Behavior (items 16, 20, 21, 23, 26, 39, 43, $67,81,82,106$ ), and Aggressive Behavior (items $3,7,19,37,57,68,90,94,95)$. Thought Problems could not be studied because frequencies of problems comprising this syndrome were too low in the present sample.

In addition to the cross-informant syndrome constructs, the total problem score and the Internalizing/Externalizing groupings of problem behavior were studied. The total problem score is the sum of all 118 close-ended items and can be viewed as an overall index of the number and severity of reported problems. It contains items not present in the scales for one of the cross-informant syndrome constructs. Groupings of problem behavior similar to the Internalizing/Externalizing groupings appear frequently in child clinical literature (Achenbach, 1991, p. 63). Internalizing comprises the items from the Withdrawn, Somatic Complaints, and Anxious/ Depressed scales; Externalizing comprises the items from the Delinquent Behavior and Aggressive Behavior scales.

\section{Sample}

The sample was part of a larger sample of 2148 international adoptees living in the Netherlands (for a full description of this sample see Verhulst et al., 1990a,b). This subset of 758 adoptees consisted of two groups of siblings and one group of singletons. The mean age of these subjects at the time of the study was 12.4 years $(\mathrm{SD}=1.2$ years). The mean age at placement in Dutch adoptive homes was 26.9 months (SD $=23.0$ months). Dutch adoption agency policies do not include selective placement, thus characteristics of the adoptees biological home environment are unrelated to those of the adoptive homes. There was only one pair of adoptees per family.

The first group of siblings consisted of 111 pairs of biologically related adoptees. This group was further divided into 35 pairs of girls, 30 pairs of boys and 46 opposite-sex pairs. The second group of siblings consisted of 221 pairs of biologically unrelated adoptees. In this group there were 48 pairs of girls, 44 pairs of boys, and 129 opposite-sex pairs. The third group consisted of 94 adoptees who grew up as the only child. This group included 44 girls and 50 boys. In all, there were $8(2 \times 3+2)$ groups.

Background characteristics of the groups of biological siblings, nonbiological siblings, and singletons are presented in Tables I and II [for a detailed discussion of the relation between these variables and problem behaviors, see Verhulst et al. . (1990a,b, 1992)]. Table I displays the countries of origin. Biological siblings and $75 \%$ of the nonbiological sibling pairs came from the same country of origin. To test the association between country of origin and group membership, this dependence in the data was removed by randomly selecting one child from each pair. The chi-square test on the country $\times$ group table indicated that there were significant differences among the three groups concerning the countries of origin $\left(\chi_{8}^{2}=67.5, p<.000\right)$. Table I shows that the group of biological siblings differed from the other two groups. Relatively more biological siblings came from Korea and Columbia versus other Asian countries and Europe.

Table II displays age (AGE, measured in years), age at placement in the adoptive home (PLACEMENT, measured in months), parental occupation [OCCUPATION; $1=$ lowest occupational level, $6=$ highest, when both parents were employed the highest level was used (Van Westerlaak et al., 1975)], the number of changes in caretaking environment (CARETAKING) the child experienced before he/she was adopted, whether the child had been neglected or abused (NEGLECT and ABUSE,

Table I. Countries of Origin for Adoptees

\begin{tabular}{lccc}
\hline & $\begin{array}{c}\text { Niological } \\
\text { sibs }\end{array}$ & $\begin{array}{c}\text { Non- } \\
\text { biological } \\
\text { sibs }\end{array}$ & Singletons \\
\hline Number of subjects & 222 & 442 & 94 \\
Korea & $47.3 \%$ & $21.5 \%$ & $20.2 \%$ \\
Other Asian & $18.0 \%$ & $43.7 \%$ & $37.2 \%$ \\
Colombia & $26.6 \%$ & $13.3 \%$ & $8.5 \%$ \\
Other Non-European & $5.4 \%$ & $7.2 \%$ & $7.4 \%$ \\
Europe & $2.7 \%$ & $14.2 \%$ & $26.6 \%$ \\
\hline
\end{tabular}

${ }^{a}$ Biological siblings and $75 \%$ of nonbiological siblings come from the same country of origin. 
Table II. Means and Standard Deviations on Background Variables and $\chi^{2}$ Test of Differences Between Groups ${ }^{a}$

\begin{tabular}{|c|c|c|c|c|c|c|c|c|}
\hline \multirow[b]{2}{*}{ Number of subjects } & \multicolumn{2}{|c|}{ Biological Sibs } & \multicolumn{2}{|c|}{ Nonbiological sibs } & \multicolumn{2}{|c|}{ Singletons } & \multicolumn{2}{|c|}{$x^{2}$} \\
\hline & & 222 & & 442 & & 94 & & \\
\hline AGE & 12.5 & $(1.18)$ & 12.4 & $(1.15)$ & 12.5 & $(1.16)$ & $\chi_{4}^{2}=2.20$ & $(p<.699)$ \\
\hline PLACEMENT & 43.5 & $(21.4)$ & 20.7 & $(20.4)$ & 17.2 & $(17.6)$ & $\hat{x}_{4}^{2}=124$. & $(p<.000)$ \\
\hline OCCUPATION & 4.71 & $(1.39)$ & 4.63 & $(1.42)$ & 4.00 & $(1.49)$ & $\hat{\chi}_{8}^{2}=18.6$ & $(p<.017)$ \\
\hline CARETAKING & 1.76 & $(.63)$ & 1.48 & $(.60)$ & 1.41 & $(.53)$ & $\chi_{2}^{2}=15.2$ & $(p<.001)$ \\
\hline NEGLECT & 1.75 & $(.82)$ & 1.54 & $(.75)$ & 1.39 & $(.64)$ & $x_{4}^{2}=9.55$ & $(p<.049)$ \\
\hline ABUSE & 1.29 & $(.58)$ & 1.13 & $(.43)$ & 1.04 & $(.19)$ & $\hat{x}^{2}{ }^{4}=16.3$ & $(p<.000)$ \\
\hline HEALTH & 1.40 & $(.49)$ & 1.41 & $(.49)$ & 1.42 & $(.50)$ & $x_{2}^{2}=.263$ & $(p<.877)$ \\
\hline
\end{tabular}

a Standard deviations in parentheses. Age measured in years, placement measured in months, and the level of parental occupation is the mean of a six-step scale.

both with categories $1=$ not, 2 = somewhat, $3=$ severe), and the child's medical condition at the time of placement (HEALTH: $1=$ healthy, $2=$ not healthy). For CARETAKING, NEGLECT, and ABUSE about $30 \%$ of the adoptive parents were not sure about their answers; their information was not used.

For the continuous variables $A G E$ and PLACEMENT, LISREL was used to test for equal distributions of the background variables in the three groups by constraining means and standard deviations to be equal. For the categorial variables OCCUPATION, CARETAKING, NEGLECT, ABUSE, and HEALTH, the background variable $\times$ group tables were analyzed to test for equal distributions. To obtain expected cell frequencies $\geq 5$, CARETAKING was recoded in two categories (one change and more than one change in caretaking environment), and categories 2 and 3 of ABUSE and categories 1 and 2 of OCCUPATION were joined. Except for AGE and HEALTH there were significant differences among the three groups. Inspection of Table II suggested that for PLACEMENT, biological siblings were placed in their adoptive homes later than were the nonbiological siblings and singletons. For OCCUPATION, CARETAKING, NEGLECT, and ABUSE, biological siblings had higher scores than nonbiological siblings, and nonbiological siblings had higher scores than singletons.

A $t$ test was used to examine differences in sibship size between biological siblings and nonbiological siblings. The sibship size was 3.32 for biological siblings and 3.01 for nonbiological siblings, which is nonsignificant $(t=1.89$, df $=330$, $p<.059$ ) at a level of .05 . The mean age difference, which may be important with respect to sibling effects, of 1.4 years for biological siblings and 1.6 years for nonbiological siblings also did not differ significantly between the two groups $(t=-1.62$, $\mathrm{df}=330, p<.106)$.

\section{Model}

The model used for genetic analyses is presented in Eq. (1) for opposite-sex pairs (subscript $\mathrm{g}$ refers to girls, subscript b refers to boys).

$$
\begin{aligned}
& P 1=s P 2+h_{\mathrm{g}} A_{1}+c_{\mathrm{g}} C_{1}+e_{\mathrm{g}} E_{1} \\
& P 2=s P 1+h_{\mathrm{b}} A_{2}+c_{\mathrm{b}} C_{2}+e_{\mathrm{b}} E_{2}
\end{aligned}
$$

$P 1$ and $P 2$ represents the scores of the first and second sibling, respectively. $A$ refers to the additive genetic factor, $C$ to the shared environmental factor, and $E$ to the nonshared environmental factor. Parameters $h, c$, and $e$ are the loadings from $P$ on $A, C$, and $E$, respectively. Parameter $\mathrm{s}$ is the effect from one sibling's behavior on the behavior of the other and does not depend on the sex of the child.

A path diagram of the model is depicted in Fig. 1. For the biological siblings, who were assumed to be full siblings, the genetic correlation $r$ was fixed at .5. For the non-biological siblings $r$ was fixed at 0 .

\section{Sibship Size Effects}

Parameter $s$ in Eq. (1) represents the direct effect of one sibling's behavior on the behavior of the other (see Carey, 1986; Eaves, 1976; Neale and Cardon, 1992). When $s$ is positive, siblings cooperate or imitate each others behaviors. Negative 


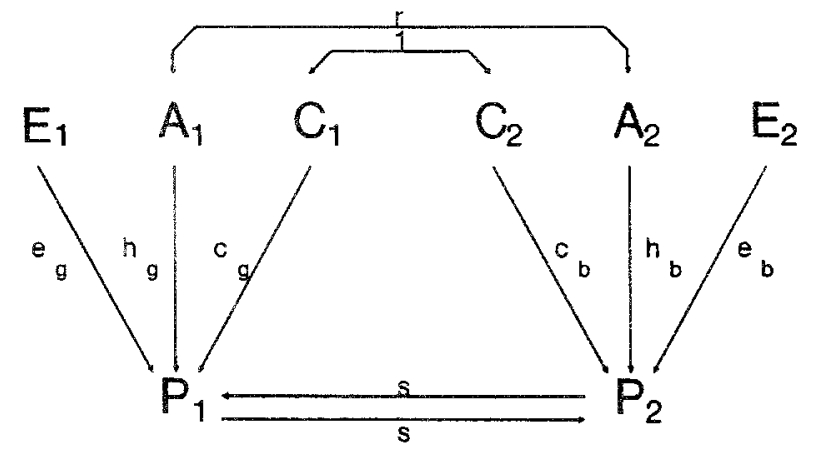

Fig. 1. A model for sibling resemblance. $P$ is observed behavior, $A$ is the additive genetic factor, $C$ is the shared environmental factor, and $E$ is the nonshared environmental factor. Parameter $h$ is the additive genetic effect, $c$ is the shared environmental effect, and $e$ is the nonshared environmental effect. Subscript g refers to girls; subscript $b$, to boys. Genetic correlation $r$ equals .5 for biological siblings and .0 for nonbiological siblings.

values imply contrast or competition effects. For example, destructive behavior in one child may, in the case of cooperation/imitation effects, evoke similar behavior in the other. The model specifies that this imitated behavior in its turn reinforces the destructive behavior of the first sibling. These interactions continue until an equilibrium is reached. For an interaction process that equilibrates, $s$ will be between -1 and 1 . More extreme values of $s$ are not realistic because they imply infinite scale scores. Parameter $s$ influences both variances and covariances between siblings. Equation (2) expresses the observed variance in case of sibling interaction [this equation is a simple elaboration of the equations presented by Neale and Cardon (1992, p. 208) and Carey (1986) to the case of sex differences]. When $A, C$, and $E$ are scaled to have variances equal to 1 , then

$$
\begin{gathered}
\operatorname{VAR}\left(P_{1}\right) \\
=\frac{\left(h_{\mathrm{g}}^{2}+2 r s h_{\mathrm{g}} h_{\mathrm{b}}+s^{2} h_{\mathrm{b}}^{2}\right)+\left(c_{\mathrm{g}}^{2}+2 s c_{c_{\mathrm{b}}}+s^{2} c_{\mathrm{b}}^{2}\right)+\left(e_{\mathrm{g}}^{2}+s^{2} e^{2}\right)}{\left(1-s^{2}\right)^{2}}
\end{gathered}
$$

Equation (2) illustrates that in the case of sibling interaction, variances for biological siblings will differ by a factor $s h_{\mathrm{g}} h_{\mathrm{b}}$ from variances for nonbiological siblings, because genetic correlation $r$ is .5 for the first group and 0 for the second. In addition, the variances for singletons will be different from the variances for the siblings $[s=0$ in Eq. (2)]: $\operatorname{VAR}\left(P_{\text {singletons }}\right)=h^{2}+c^{2}+e^{2}$. Such differ- ences in observed variances among the groups of biological siblings, nonbiological siblings, and singletons form part of the basis of estimating sibling effects.

However, variances for siblings and singletons may be different for reasons other than active influences from siblings on each other. For instance, as the number of children in the family increases, there could be a decrease in the amount of time parents spend with each child. In this case sibship size represents an aspect of the shared environment. Children in the groups of siblings come from families of different sizes, but for singletons sibship size is not a source of variation. Consequently, the variance for singletons will be smaller than for siblings. In terms of Eq. (1), these sibship size effects could be accounted for by estimating a separate shared environmental effect in the group of singletons. The variance for siblings and singletons can then be expressed as $\operatorname{VAR}\left(P_{\text {sibiings }}\right)=$ $h^{2}+c_{\text {siblings }}^{2}+e^{2}$, and $\operatorname{VAR}\left(P_{\text {singletons }}\right)=$ $h^{2}+c^{2}$ singletons $+e^{2}$, with $c_{\text {siblings }}^{2} \geq c^{2}$ singletons"

The two models for sibship size effects lead to different predictions and are, therefore, testable alternatives. In contrast to a model with sibling effects, the model which views sibship size as an aspect of the shared environment does not predict different variances for biological and nonbiological siblings. Furthermore, when shared environmental effects are not important, this model cannot account for a difference in variance between singletons and siblings, while a model with sibling interaction can. Finally, the shared environment model does not affect covariances between siblings, while models with sibling interaction do (Neale and Cardon, 1992, p. 208).

\section{Sex Differences}

To account for sex differences, models with general scalar sex limitation and specific scalar sex limitation were fitted (Heath et al., 1989; Neale and Martin, 1989). Both models assume that the same genes and environments are important for problem behavior in girls and boys but allow the magnitude of their effects to be different. In a model with general scalar sex limitation, the sex difference in magnitude is assumed to be the same for all three parameters, $h, c$, and $e$. In a model with specific scalar sex limitation, the sex difference can be different for each separate parameter. The former model is more parsimonious because it esti- 
mates only one additional parameter compared to a model without sex differences, while the latter model estimates three additional parameters $(h, c$, and $e$ are estimated for girls and boys separately). A model with general scalar sex limitation can account for differences in variances between girls and boys, but the relative importance of genetic (the heritability) and environmental influences is the same. In a model with specific scalar sex limitation, also the relative importance of genetic and environmental influences can be different for girls and boys.

\section{Model Selection and Simplification}

To select the best-fitting model, four variations of Eq. (1) were fitted to the data. Models with either general scalar sex limitation or specific scalar sex limitation were elaborated with parameter $\mathrm{s}$ for sibling interaction or with separate shared environmental effects for singletons. The model with the largest probability ( $p$ value) was preferred.

To obtain parsimonious models, chi-square difference tests were performed to examine whether parameters of the preferred model could be fixed at zero or constrained to be equal for both sexes. Nonshared environmental influences were not fixed at zero because they are confounded with errors of measurement, and perfectly reliable scales are not realistic.

To perform accurate significance tests with maximum-likelihood estimation, the absolute standardized skewnesses and kurtoses of the variables have to be smaller than 1 (Muthén and Kaplan, 1985). However, for the 10 scales the mean absolute skewness and kurtosis were 2.06 and 5.18, respectively. Only the kurtosis of Attention Problems. was smaller than 1 . Log-transformations were performed to approximate normality. These transformations improved the mean skewness and kurtosis to .758 and .455 , respectively, and only the skewness of Somatic Problems and Social Problems still exceeded 1.

\section{Power}

A number of analyses [using LISREL (see Jöreskog and Sörbom, 1989, pp. 217-218)] showed that the power to detect genetic effects was lowest. For instance, for a model without sex differences, $30 \%$ genetic variance, $10 \%$ shared environmental variance, and $60 \%$ nonshared environmental variance, the power to detect genetic effects with $p<.20$ is .52 (with $p<.05$ the power is only .26). With larger amounts of shared environmental influences the power to detect genetic effects improves a little, but it is unlikely that this represents a more realistic situation. The power to detect similar effects of other parameters was higher. For instance, in the above situation sibling interactions of $s=.25$ would result in a mean increase in variance of about $30 \%$ in the sibling groups. The power to detect these sibling cooperation/imitation effects with $p<.20$ is .63. The highest power was to detect shared environmental influences. For instance, with equal proportions of genetic and nonshared environmental variance, the power to detect only $10 \%$ shared environmental variance is already .58 with $p<.20$.

In summary, with the usual $p<.05$ the power was too low for almost all parameters. To obtain a reasonable power to detect at least moderate effects of each parameter, $p<.20$ was used for the significance tests.

\section{LISREL Specification}

LISREL 7 was used to obtain parameter estimates through a simultaneous analysis of the eight groups in the sample. LISREL requires that every group has the same number of variables. However, for singletons there is only one observed variable, and a dummy variable $D$ with pseudovalues $\operatorname{VAR}(D)=1$ and $\operatorname{COV}(\mathrm{P} 1, D)=0$ was therefore specified in these groups [analogous to the way missing data can be handled in LISREL (Jöreskog and Sörbom, 1989, p. 259)]. For the eight groups there were $20(6 \times 3+2)$ observed statistics and 4 $(2 \times 2)$ statistics associated with the dummy variables. The degrees of freedom were adjusted for these dummy variables by putting $\mathrm{df}=4$ on the OU line of the last group.

The implementation of models with sibling interaction, general scalar sex limitation, and specific scalar sex limitation can be achieved by approaches illustrated by Heath et al. (1989), Neale and Cardon (1992), and Neale and Martin (1989).

For models with general scalar sex limitation and smaller shared environmental effects for singletons, shared environmental effects were estimated for singletons separately. For models with specific scalar sex limitation and smaller shared environmental effects for singletons, the $B$ matrix of LISREL was used [analogous to the way parameter estimates can be constrained to be nonnegative (see Neale and Martin, 1989)]. For singletons one ad- 
ditional parameter $\mathrm{b}$ was estimated in the $\mathrm{B}$ matrix, while for siblings the corresponding parameter was fixed at 1 . The shared environmental effects for girls and boys in the groups of singletons can be obtained by multiplying the shared environmental effect for girls $c_{\mathrm{g}}$ and boys $c_{\mathrm{b}}$ in the sibling groups with $b$. This procedure is in agreement with a model of specific scalar sex limitation and results in the same scalar sex difference in shared environmental effects for singletons and siblings.

\section{RESULTS}

Table III reports variances for families of different sibship sizes and correlations between sibship size and scale scores. Results in Table III are based on the whole sample of 2148 international adoptees. Sibship size was computed by summing all biological, adoption, and foster children in a given family. A six-group analysis in LISREL (with random selection of one child from each sibling pair) showed that for the total problem score, Withdrawn, Social Problems, Externalizing, Delinquent Behavior, and Aggressive Behavior, there were significant differences in variances for the six groups of different sibship size. Most scales showed a substantial increase in variance up to sibship sizes of four.

Although correlations between sibship size and Withdrawn and Delinquent Behavior were significant (for the significance test one child was randomly selected from each sibling pair), they were very small. The absence of substantial positive or negative correlations implies that having siblings can, in general, be considered neither beneficial nor harmful. To examine possible nonlinear relationships, regression analyses were performed with a second-degree polynomial. Compared to the correlations in Table III the multiple correlations did not improve more than a factor of .05 . Only for Withdrawn did the polynomial explain more than $1 \%$ of the variance (the adjusted $r^{2}$ was .013). This indicated that there were no substantial nonlinear relations between sibship size and problem behavior either.

Sibling correlations are given in Table IV. Inspection of Table IV suggests a number of trends. For the total problem score, sibling correlations were larger compared to those for other scales and somewhat larger for biological siblings than for nonbiological siblings. For Internalizing behaviors, sibling correlations were equal or even somewhat smaller for biological siblings than for nonbiological siblings. For Externalizing behaviors sibling correlations tended to be larger for biological siblings than for nonbiological siblings.

Table $\mathrm{V}$ presents the results from testing for differences in variances and fitting various baseline models. Model 1 constrains for same-sex groups the variance of the first sibling to the variance of the second sibling. Especially for Social Problems and Delinquent Behavior the fit of model 1 was poor. This poor fit was probably caused by chance, because a random procedure was used to determine the first and second sibling. The implication of this is that, for these scales, one cannot expect a good fit of any of the other models and that a poor fit does not necessarily refer to an inappropriate model.

Model 2 constrains variances to be equal for

Table III. Variances for Log-Transformed CBCL Scales for Different Sib Sizes, $\chi^{2}$ Test for Differences in Variances Between Groups, and Correlations $(r)$ Between Sibship Size and Scales

\begin{tabular}{|c|c|c|c|c|c|c|c|c|c|}
\hline Sib size & 1 & 2 & 3 & 4 & 5 & $\geq 6$ & $x_{4}^{2}$ & (prob.) & $r$ \\
\hline Number of subjects & 94 & 960 & 554 & 351 & 104 & 81 & & & 2148 \\
\hline Total score & .62 & .74 & .79 & .83 & .72 & .80 & 16.5 & $(.006)$ & .00 \\
\hline Internalizing & .41 & .39 & .45 & .43 & .46 & .35 & 7.6 & $(.180)$ & .05 \\
\hline Withdrawn & .41 & .44 & .52 & .51 & .59 & .39 & 17.1 & $(.004)$ & $.07 *$ \\
\hline Somatic complaints & 53 & 50 & 48 & 48 & 53 & 47 & 1.3 & $(.932)$ & -.01 \\
\hline Anxious/depression & .50 & .49 & .52 & .57 & .52 & .44 & 9.7 & $(.084)$ & .01 \\
\hline Social Problems & 86 & 87 & 94 & 109 & 116 & 80 & 30.5 & $(.000)$ & .03 \\
\hline Attention Problems & .10 & .12 & .11 & .12 & .13 & .10 & 10.6 & $(.061)$ & -.01 \\
\hline Externalizing & .45 & .51 & .60 & .66 & .63 & .60 & 16.3 & $(.006)$ & .00 \\
\hline Delinquent Behavior & .79 & .86 & 1.0 & 1.1 & 1.2 & .96 & 15.8 & $(.008)$ & $.06 *$ \\
\hline Aggressive Behavior & .23 & .25 & .28 & .32 & .31 & .28 & 22.6 & $(.000)$ & -.03 \\
\hline
\end{tabular}


Table IV. Observed Correlations for Biological and Nonbiological Siblings, for log-Transformed CBCL Scales

\begin{tabular}{|c|c|c|c|c|c|c|}
\hline & \multicolumn{3}{|c|}{ Biological sibs } & \multicolumn{3}{|c|}{ Nonbiological sibs } \\
\hline & Girls & Boys & Girls/boys & Girls & Boys & Girls/boys \\
\hline Numbers of pairs & 35 & 30 & 46 & 48 & 44 & 129 \\
\hline Total score & .590 & .519 & .638 & .566 & .475 & .339 \\
\hline Internalizing & .156 & .152 & .312 & .414 & .441 & .280 \\
\hline Withdrawn & .139 & .152 & .064 & .310 & .130 & .127 \\
\hline Somatic complaints & .260 & .254 & -.006 & .538 & -.118 & .080 \\
\hline Anxious/depression & .080 & .213 & .328 & .199 & .327 & .229 \\
\hline Social Problems & .280 & .141 & .294 & .234 & .347 & .117 \\
\hline Attention Problems & .143 & .169 & .465 & -.126 & .089 & .086 \\
\hline Externalizing & .425 & .463 & .516 & .372 & .190 & .114 \\
\hline Delinquency & .148 & .418 & .452 & .304 & .266 & .123 \\
\hline Aggression & .446 & .404 & .384 & .211 & .024 & .046 \\
\hline
\end{tabular}

Table V. Chi-Squares Obtained from Fitting Baseline Models ${ }^{a}$

\begin{tabular}{|c|c|c|c|c|c|c|}
\hline & Model 1 & Model 2 & Model 3 & Model 4 & Model 5 & Model 6 \\
\hline & $(\mathrm{df}=4)$ & $(\mathrm{df}=12)$ & $(\mathrm{df}=12)$ & $(\mathrm{df}=13)$ & $(\mathrm{df}=15)$ & $(\mathrm{d} f=15)$ \\
\hline Total problem score & $\begin{array}{l}1.76 \\
(.780)\end{array}$ & $\begin{array}{l}8.63 \\
(.735)\end{array}$ & $\begin{array}{l}9.40 \\
(.742)\end{array}$ & $\begin{array}{l}\mathbf{8 . 8 4} \\
(.785)\end{array}$ & $\begin{array}{c}11.11 \\
(.745)\end{array}$ & $\begin{array}{r}11.61 \\
(.708)\end{array}$ \\
\hline Internalizing grouping & $\begin{array}{l}2.95 \\
(.566)\end{array}$ & $\begin{array}{l}8.46 \\
(.748)\end{array}$ & $\begin{array}{r}12.45 \\
(.491)\end{array}$ & $\begin{array}{c}12.45 \\
(.491)\end{array}$ & $\begin{array}{c}12.50 \\
(.641)\end{array}$ & $\begin{array}{r}12.50 \\
(.641)\end{array}$ \\
\hline Withdrawn & $\begin{array}{l}6.58 \\
(.160)\end{array}$ & $\begin{array}{r}15.58 \\
(.211)\end{array}$ & $\begin{array}{c}16.52 \\
(.222)\end{array}$ & $\begin{array}{c}16.30 \\
(.233)\end{array}$ & $\begin{array}{c}17.50 \\
(.290)\end{array}$ & $\begin{array}{c}17.00 \\
(3.19)\end{array}$ \\
\hline Somatic complaints & $\begin{array}{l}4.38 \\
(.357)\end{array}$ & $\begin{array}{c}13.39 \\
(.341)\end{array}$ & $\begin{array}{c}\mathbf{1 8 . 4 4} \\
(.142)\end{array}$ & $\begin{array}{c}17.11 \\
(.194)\end{array}$ & $\begin{array}{r}28.26 \\
(.020)\end{array}$ & $\begin{array}{r}28.26 \\
(.020)\end{array}$ \\
\hline Anxious/depressed & $\begin{array}{l}3.42 \\
(.490)\end{array}$ & $\begin{array}{l}9.11 \\
(.693)\end{array}$ & $\begin{array}{l}9.75 \\
(.715)\end{array}$ & $\begin{array}{l}9.62 \\
(.724)\end{array}$ & $\begin{array}{c}10.22 \\
(.806)\end{array}$ & $\begin{array}{r}10.20 \\
(.807)\end{array}$ \\
\hline Social Problems & $\begin{array}{l}9.73 \\
(.045)\end{array}$ & $\begin{array}{c}20.56 \\
(.027)\end{array}$ & $\begin{array}{c}21.37 \\
(.066)\end{array}$ & $\begin{array}{l}22.06 \\
(.054)\end{array}$ & $\begin{array}{r}22.57 \\
(.094)\end{array}$ & $\begin{array}{r}22.24 \\
(.102)\end{array}$ \\
\hline Attention Problems & $\begin{array}{l}1.03 \\
(.905)\end{array}$ & $\begin{array}{l}9.75 \\
(.638)\end{array}$ & $\begin{array}{r}13.97 \\
(.376)\end{array}$ & $\begin{array}{r}13.68 \\
(.397)\end{array}$ & $\begin{array}{r}14.13 \\
(.516)\end{array}$ & $\begin{array}{r}13.81 \\
(.540)\end{array}$ \\
\hline Externalizing grouping & $\begin{array}{l}3.96 \\
(.412)\end{array}$ & $\begin{array}{c}19.73 \\
(.072)\end{array}$ & $\begin{array}{c}20.41 \\
(.085)\end{array}$ & $\begin{array}{c}16.19 \\
(.239)\end{array}$ & $\begin{array}{c}23.45 \\
(.075)\end{array}$ & $\begin{array}{c}21.35 \\
(.126)\end{array}$ \\
\hline Delinquent Behavior & $\begin{array}{c}10.08 \\
(.039)\end{array}$ & $\begin{array}{c}24.43 \\
(.018)\end{array}$ & $\begin{array}{r}24.42 \\
(.027)\end{array}$ & $\begin{array}{l}23.91 \\
(.032)\end{array}$ & $\begin{array}{r}25.33 \\
(.046)\end{array}$ & $\begin{array}{r}24.47 \\
(.057)\end{array}$ \\
\hline Aggressive Behavior & $\begin{array}{l}.80 \\
(.938)\end{array}$ & $\begin{array}{c}14.08 \\
(.296)\end{array}$ & $\begin{array}{c}13.94 \\
(.378)\end{array}$ & $\begin{array}{c}10.52 \\
(.651)\end{array}$ & $\begin{array}{r}16.97 \\
(.321)\end{array}$ & $\begin{array}{r}15.85 \\
(.392)\end{array}$ \\
\hline
\end{tabular}

a Model 1 constrains the variances of the first and second sibling equal to each other, within same-sex sibling groups. Model 2 constrains variances equal across groups, for girls and boys separately. Model 3 allows general scaler sex limitation and sibling interaction. Model 4 allows general scalar sex limitation and smaller shared environmental influences for singletons. Model 5 allows specific scalar sex limitation and sibling interaction. Model 6 allows specific scalar sex limitation and smaller shared environmental influences for singletons. Boldface number denotes preferred model. Probabilities are in parentheses.

biological siblings, nonbiological siblings, and singletons. Model 2 is nested within model 1, and the chi-square difference test could be used to test model 1 against model $2(p<.20)$. The decrease in fit was significant for the Externalizing grouping, Delinquent Behavior, and Aggressive Behavior. For these scales, variances were not equal across groups which could refer to an effect of sibship size.

Models 3 and 4 are models with specific scalar sex limitation. Model 3 also allows sibling interaction. Model 4 does not allow sibling interaction but estimates parameter $b$ to account for possible 
smaller shared environmental effects in the groups of singletons. Models 5 and 6 are models with general scalar sex limitation. Model 5 allows sibling interaction. Model 6 does not allow sibling interaction but estimates shared environmental effects for singletons separately.

For the Internalizing grouping, Withdrawn, Somatic Complaints, Anxious/Depressed, Social Problems, and Attention Problems significance tests showed that there were no significant sibling interactions or smaller shared environmental effects for singletons. This explains the small differences between model 3 and model 4 and between model 5 and model 6 for these scales. The choice of which model to prefer is therefore trivial, because when both models are simplified, the same results obtain. In principle, the choice for these scales is between models with specific and those with general scalar sex limitation, and in Table $V$ either models 3 and 4 or models 5 and 6 are boldfaced. For Externalizing and Aggressive Behavior there were significant smaller shared environmental effects in singletons, but no significant sibling effects. Moreover, for the preferred models with specific scalar sex limitation, the model with smaller shared environmental effects for singletons fitted better. For the total problem score and Delinquent behavior the choice was more difficult. There were both significant smaller shared environmental effects for singletons and sibling effects. However, the former model fitted slightly better and was therefore preferred.

Estimates of the parameters of the preferred model and the model that resulted from simplifying the preferred model are shown in Table VI (the model with the highest $p$ value was preferred). Results confirmed trends shown in Table IV. For Internalizing scales genetic influences were small or absent, and nonshared environmental influences were largest. For Externalizing scales genetic influences were larger than either shared or nonshared environmental influences.

Sex differences were significant for 8 of the 10 scales. For scales with general scalar sex limitation Anxious/Depressed, Social Problems, Attention Problems, and Delinquent Behavior, genetic and environmental effects were significantly larger for boys. For scales with specific scalar sex limitation, the total problem score, Somatic Complaints, the Externalizing grouping, and Aggressive Behavior genetic effects were larger but shared environmental effects were significantly smaller for boys.

\section{DISCUSSION}

Results from the present adoption study showed that genetic effects varied widely across specific CBCL scales. Genetic effects were important for Attention Problems and Externalizing scales but were almost zero for Internalizing scales. To what extent do these findings confirm twin study inferences about genetic and environmental effects on problem behaviors in children and adolescents?

Total Problem Score. Edelbrock et al. (1992) studied 99 pairs $\mathrm{MZ}$ and 82 pairs of same-sex DZ twins (mean age, 11.0 years). Ratings of twins' problem behaviors were obtained with the $\mathrm{CBCL}$. Genetic, shared environmental, and nonshared environmental influences accounted for 32,48 , and $20 \%$ of the variance of the total problem score. These findings are in close agreement with those from the present study. When for sake of comparison sex differences are ignored and findings are pooled for boys and girls, the percentages in our study are 31,41 , and $27 \%$, respectively. A twin study by Graham and Stevenson (1985) and three twin studies reported by Shields (1977) also found evidence of genetic influences on a general measure of psychiatric dysfunctioning in children. However, compared to the CBCL total problem score, measures used in the latter studies showed somewhat smaller shared environmental influences.

Internalizing Scales. Two twin studies showed substantial genetic influences for the CBCL Internalizing grouping (Hewitt et al., 1992; Edelbrock et al., 1992). In other twin studies similar results were obtained for Internalizing problems such as anxiety and depression (Gottesman, 1963; 1965; Scarr, 1966; Stevenson et al., 1992; Wierzbicki, 1987). In the present study these findings could not be replicated. Genetic influences on the Internalizing scales were small or absent and nonshared environmental influences were large.

Attention Problems. For Attention Problems, genetic influences accounted for $47 \%$ of the variance, whereas shared environmental influences were very small. This finding is in close agreement with the CBCL study by Edelbrock et al. (1992) and, also, agrees with the majority of twin studies using other measures of hyperactivity/activity (Goodman and Stevenson, 1989b; O'Connor et al., 1980; Matheny \& Dolan, 1980; Plomin, 1986, p. 214; Torgersen, 1982; Willerman, 1973).

Externalizing scales. For the Externalizing scale genetic influences accounted for $65 \%$ of the vari- 
Table IV. Parameter Estimates from Fitting the Preferred Model (Table V) and the Best-Fitting Simplified Model $^{a}$

\begin{tabular}{|c|c|c|c|c|c|c|c|c|c|}
\hline & \multicolumn{9}{|c|}{ General scalar sex limitation } \\
\hline & df & & $\chi^{2}$ & $h$ & & & $e$ & & Scalar \\
\hline \multirow[t]{2}{*}{ Internalizing grouping } & 15 & & 12.50 & .000 & \multicolumn{2}{|c|}{$.347 / .336$} & .532 & \multicolumn{2}{|r|}{1.048} \\
\hline & 18 & & 13.38 & - & \multicolumn{2}{|c|}{.354} & .544 & \multicolumn{2}{|r|}{1.000} \\
\hline \multirow[t]{2}{*}{ Withdrawn } & 15 & & 17.00 & .000 & \multicolumn{2}{|c|}{$.250 / .096$} & .616 & \multirow{2}{*}{\multicolumn{2}{|c|}{$\begin{array}{l}1.056 \\
1.000\end{array}$}} \\
\hline & 18 & & 18.75 & - & \multicolumn{2}{|c|}{.253} & .629 & & \\
\hline \multirow[t]{2}{*}{ Anxious/depressed } & 15 & & 10.20 & .134 & \multicolumn{2}{|c|}{$.333 / .313$} & .589 & \\
\hline & 17 & & 10.25 & - & \multicolumn{2}{|c|}{.335} & .601 & \multicolumn{2}{|r|}{1.085} \\
\hline \multirow[t]{2}{*}{ Social Problems } & 15 & & 22.24 & 3.60 & \multicolumn{2}{|c|}{$3.87 / 2.55$} & 7.31 & \multicolumn{2}{|r|}{1.138} \\
\hline & 17 & & 23.22 & - & \multicolumn{2}{|c|}{4.08} & 7.99 & \multicolumn{2}{|r|}{1.136} \\
\hline \multirow{2}{*}{ Attention Problems } & 15 & & 13.81 & .217 & \multicolumn{2}{|c|}{$.079 / .000$} & .217 & \\
\hline & 17 & & 14.78 & .242 & \multicolumn{2}{|c|}{-} & .205 & \multicolumn{2}{|r|}{1.105} \\
\hline \multirow[t]{4}{*}{ Delinquent Behavior } & 15 & & 24.47 & .527 & \multirow{2}{*}{\multicolumn{2}{|c|}{$\begin{array}{c}.363 / .042 \\
.362 /-\end{array}$}} & .550 & & \\
\hline & 16 & & 24.47 & .528 & & & .549 & \multicolumn{2}{|r|}{1.257} \\
\hline & \multicolumn{9}{|c|}{ Specific scalar sex limitation } \\
\hline & $\mathrm{df}$ & $x^{2}$ & $h_{g}$ & $h_{\mathrm{b}}$ & $c_{\mathrm{g}}$ & $c_{\mathrm{b}}$ & $e_{\mathrm{g}}$ & $e_{\mathrm{b}}$ & $\beta$ \\
\hline \multirow[t]{2}{*}{ Total problem score } & 13 & 8.84 & .385 & .592 & .639 & .487 & .423 & .443 & .671 \\
\hline & 14 & 8.85 & .378 & .485 & .640 & .428 & .448 & .448 & .670 \\
\hline \multirow[t]{2}{*}{ Somatic Complaints } & 13 & 17.11 & -.250 & 4.36 & 4.42 & .524 & 5.61 & 5.03 & 1.37 \\
\hline & 17 & 19.62 & - & 3.60 & 4.63 & - & 5.62 & 5.62 & 1.00 \\
\hline \multirow[t]{2}{*}{ Externalizing grouping } & 13 & 16.19 & .444 & .742 & .420 & .173 & .263 & .197 & .000 \\
\hline & 15 & 16.22 & .453 & .725 & .419 & .176 & .250 & .250 & - \\
\hline Aggressive Behavior & 13 & 10.52 & .319 & .499 & .256 & .040 & .183 & .242 & .000 \\
\hline & 16 & 10.88 & .322 & .526 & .253 & - & .180 & .180 & - \\
\hline
\end{tabular}

ance. The remainder consisted of almost equal parts of shared and nonshared environmental influences. $\mathrm{MZ/DZ}$ twin correlations of .79 (99 pairs)/.53 (82 pairs) in the CBCL study by Edelbrock et al. (1992) and 72 (54 pairs)/.42 (33 pairs) in a twin study of the Bullying scale from the Conners Parent Symptom Rating questionnaire (O'Connor et al., 1980) yielded results roughly in line with those in the present study. However, a CBCL study by Hewitt et al. (1992) involving $414 \mathrm{MZ}$ and $569 \mathrm{DZ}$ twin pairs clearly suggested larger shared environmental influences (about 60\%).

In the present study, genetic influences accounted for $70 \%$ of the variance of Aggressive Behavior. This finding is just in between results from CBCL studies by Ghodsian-Carpey and Baker (1987) and Edelbrock et al. (1992). Ghodsian-Carpey and Baker (1987) found, in a sample of 21 pairs of $M Z$ and 17 pairs of $\mathrm{DZ}$ twins, that genetic influences accounted for more than $90 \%$ of the variance of an earlier version of the CBCL Aggressive Behavior scale. On the other hand, Edelbrock et al. (1992) found a heritability of $50 \%$ for the CBCL Aggressive Behavior Scale. In the present study a higher heritability was found for the Aggressive Behavior scale than for the Delinquent Behavior scale. Edelbrock et al. (1992), who also studied both scales, reported similar results.

The heritability of .39 found in the present study for Delinquent Behavior, is in agreement with findings from twin studies by Edelbrock et al. (1992), McGuffin and Gottesman (1985), and Rowe (1983). However, a twin study employing the MMPI Psychopathic Deviate Scale (Gottesman, 1963) suggested larger genetic influences. Furthermore, the twin studies by Edelbrock et al. (1992), McGuffin and Gottesman (1985), and Rowe (1983) tended to show somewhat larger shared environmental influences in comparison to results from the present study.

In summary, for the total problem score, At- 
tention Problems, and Externalizing scales, the results of the present study were in agreement with findings from twin studies, thereby strengthening twin study inferences about genetic influences on these syndromes. The lack of genetic influences on Internalizing behaviors was in contrast with results from twin studies. Analyses showed that the power to detect genetic effects was low in the present study, and it is therefore not unlikely that the absence of genetic effects on Internalizing behaviors was due to sampling variation.

Some biases may have affected the results from the present study. It was assumed that the biological siblings were full siblings. However, within this group there could be a substantial proportion of half-siblings. To check the assumption that the biological siblings were full siblings, analyses were repeated with the genetic correlation of . 25 for halfsiblings. For scales which showed no genetic influences (e.g., Internalizing behaviors), parameter estimates and fit indices were identical to findings obtained from fitting models which assumed a genetic correlation of .5. For scales which showed genetic influences, genetic effects were larger and nonshared environmental effects were smaller. Estimates of the shared environmental effects were hardly affected. However, these models assuming a genetic correlation of .25 yielded unacceptable high heritabilities compared to the findings from twin studies such as reported above. Moreover, for some scales zero or very small nonshared environmental effects were estimated (e.g., total problem score, Attention Problems, Aggressive Behavior). Very small or zero nonshared environmental effects are not plausible, because nonshared environmental influences are confounded with errors of measurement. Finally, the fit for Aggressive Behavior was poorer for the model that assumed a genetic correlation of .25 than for the model that assumed a genetic correlation of .5 . The difference found in the correlations of biological versus nonbiological siblings for Aggressive Behavior was too large to be consistent with a model that assumed that the biological siblings were half-siblings. In conclusion, the analyses with a genetic correlation of .25 indicated that it was unlikely that a large proportion of the biological siblings was half-siblings.

It was assumed that the common environments were similar for the two groups of siblings. However, this may not be true for the time prior to adoption. The biological siblings may have experienced more equal environments than the nonbiol- ogical siblings. For instance, for a number of background variables such as whether according to the adoptive parents the child had been neglected or abused, the biological siblings were more highly correlated. To the extent that these background factors are associated with problem behavior, this could have increased similarity in the former group compared to the latter and resulted in overestimates of the heritabilities. However, the most striking finding in the present study concerns the absence of genetic effects on Internalizing scales. This suggested that the bias introduced by more similar early environments for biological siblings than for nonbiological siblings is not likely to be substantial.

Reports by Verhulst et al. (1990a,b) showed some ethnic differences in problem behaviors. The biological siblings and, in most cases, also the nonbiological siblings came from the same countries of origin, and ethnic differences could therefore have raised the sibling correlations and produced overestimates of the shared environment and underestimates of the nonshared environment. Compared to findings from twin studies, results from the present study did not suggest that shared environmental influences were overestimated. Moreover, for the Externalizing grouping and Delinquent Behavior, shared environmental influences tended to be smaller compared to shared environmental influences on similar scales in twin studies. It is therefore not likely that ethnic differences had a large impact on the results from the present study.

Adopted children may show an increased genetic vulnerability (Verhulst et al., 1990b; Rutter et al., 1990a) and often have experienced more negative environmental influences (discontinuous caretaking, deprivation/abuse, malnutrition, and medical conditions) which could put them at elevated risk for maladjustment (Verhulst et al., 1992). On the other hand, the selection of "suitable" adoptive homes seem to counteract some of the negative influences of the early environments (Tizard, 1977; Verhulst et al., 1992). Since heritability estimates are population dependent, these atypical factors could limit the generalizability to the general population and produce differences between heritabilities obtained from twin data.

For the Externalizing grouping, Delinquent Behavior, and Aggressive Behavior, significant differences in variances between siblings and singletons were found. There are a number of possible explanations for this finding. First, the distributions of a number of background variables differed sig- 
nificantly between the groups in our study. However, additional analyses showed that on average the squared adjusted multiple correlation between these background variables and the scales studied in this paper was .023. This indicated that associations between these measured background variables and problem behaviors were too small to explain group differences in variances by differences in background variables. Furthermore, variances tended to increase with sibship size. This suggested a systematic effect associated with the number of siblings. Model fit indices indicated that these differences in variances are better attributed to smaller effects of factors associated with sibship size than to active influences of siblings on each other. The low correlations between sibship size and scale scores suggested that, in general, sibship size influences can be considered neither harmful nor beneficial. Relations between sibship size and problem behaviors appeared to be more complex. For instance, it could be that the presence of multiple children may be beneficial in one situation, or family, but harmful in another. Indeed, this predicts smaller variances for singletons, but not lower or higher levels of problem behaviors.

Some caution is needed with respect to the choice between models with sibling interaction or smaller shared environmental influences for singletons. Although the power to detect moderate sibship size effects of some sort was reasonable, at $p<.20$, the distinction between sibling cooperation/ imitation effects and sibship size as an aspect of the shared environment is much more difficult to make on the basis of the fit indices. A number of analyses showed that with respect to fit, the two models are interchangeable to a certain extent. In the case of sibling cooperation/imitation the increased sibling resemblance can also be accounted for by overestimating shared environmental influences in the groups of siblings, and the smaller variances for singletons can be obtained by estimating smaller shared environmental effects in this group.

For instance, for Delinquent Behavior there was only a small difference in fit between the two models and there were also significant sibling interactions. Moreover, compared to other syndromes, a number of studies showed a somewhat larger shared environmental component for juvenile delinquency (Rutter et al., 1990b), In part, this larger shared environmental effect for delinquency may reflect the influence from one sibling on the other
(Rowe, 1983). Indeed, evidence for such influences in adult delinquency (Carey, 1992) and boys' Externalizing behaviors has been found with twin data (Neale and Cardon, 1992). This illustrates that on the basis of both the results of the present study and some other findings in this area, caution is needed in interpreting the sibship size effect.

Sex differences were found for most problem behaviors and were most obvious for the Externalizing grouping and Aggressive Behavior. For boys, genetic influences were larger and shared environmental influences smaller. The larger genetic effects explained the larger total variance for boys. Under the assumption that quantitative test scores are liabilities or "risks" to behavior problems, differences in variances may have implications for prevalence rates. Externalizing problems are more prevalent in boys (Verhulst and Koot, 1992). The larger genetic effects for boys could contribute to this larger prevalence, because it implies that more boys are at high risk for Externalizing problems.

\section{ACKNOWLEDGMENTS}

This research was supported by a grant from the Sophia Foundation for Medical Research. The authors are grateful to Mrs. Herma Versluis-den Bieman for her helpful comments.

\section{REFERENCES}

Achenbach, T. M. (1991). Integrative Guide for the $1991 \mathrm{CBCL} /$ 4-18, YSR, and TRF Profiles, Department of Psychiatry, University of Vermont, Burlington.

Carey, G. (1986). Sibling imitation and contrast effects. Behav. Genet. 16:319-341.

Carey, G. (1992). Twin imitation for antisocial behavior: Implications for genetic and family environment research. $I$. Abnorm. Psychol. 101:18-25.

Dunn, J. (1983). Sibling relationships in early childhood. Child Dev. 54:787-811.

Dunn, J., and McGuire, S. (1992). Sibling and peer relationships in childhood. J. Child Psychol. Psychiat. 33:67105.

Eaves, L. (1976). A model for sibling effects in man. Heredity 36:205-214.

Edelbrock, C., Rende, R. D., Plomin, R., and Thompson, L. A. (1992). A twin study of behavior problems in early adolescence. Behav. Genet. 22 (abstr.).

Ghodsian-Carpey, J., and Baker, L. A. (1987). Genetic and Environmental influences on aggression in 4- to 7-yearold twins. Aggress. Behav. 13:173-186.

Goodman, R., and Stevenson, J. (1989). A twin study of hyperactivity. II. The aetiological role of genes, family relationships and perinatal adversity. J. Child Psychol. Psychiat. 30:691-709.

Gottesman, I. I. (1963). Heritability of personality: A demonstration. Psychol. Monogr. 77(9): No. 572.

Gottesman, I. I. (1965). Personality and natural selection. In 
Vandenberg, S. G. (ed.), Methods and Goals in Human Behavioral Genetics, Academic Press, New York, pp. 63-81.

Heath, A. C., Neale, M. C., Hewitt, J. K., Eaves, L. J., and Fulker, D. W. (1989). Testing structural equation models for twin data using LISREL. Behav. Genet. 19:9-35.

Hewitt, J. K., Silberg, J. L., Neale, M. C., Eaves, L. J., and Erickson, M. (1992). The analysis of parental ratings of children's behavior using LISREL. Behav. Genet. 3:293318.

Jöreskog, K. G., and Sörbom, D. (1989). LðSREL 7. A Guide to the Program and Applications, SPSS, Chicago.

Matheny, A. P., and Dolan, A. B. (1980). A twin study of personality and temperament during middle childhood. $J$. Res. Personal. 14:224-234.

McGuffin, P., and Gottesman, I. I. (1985). Genetic influences on normal and abnormal development. In Rutter, M., and Hersoy, L. (eds.), Child and Adolescent Psychiatry: Modem Approaches, 2nd ed., Blackwell Scientific, Oxford, pp. 17-33.

Muthén, B., and Kaplan, D. (1985). A comparison of some methodologies for the factor analysis of non-normal Likert variables. Br. I. Math. Stat. Psychol. 38:171-189.

Neale, M. C., and Cardon, L. R. (1992). Methodology for Genetic Studies of Twins and Families, Kluwer, Dordrecht.

Neale, M. C., and Martin, N. G. (1989). The effects of age, sex, and genotype on self-report drunkenness following a challenge dose of alcohol. Behav. Genet. 19:63-78.

O'Connor, M., Foch, T., Sherry, T., and Plomin, R. (1980). A twin study of specific behavioral problems of socialization as viewed by parents. $J$. Abnorm. Child Psychol. 8:189-199.

Patterson, G. R. (1982). Coercive Family Process, Castalia, Eugene, OR.

Plomin, R. (1986). Development, Genetics and Psychology, Lawrence Erlbaum Associates, Hillsdale, NJ.

Plomin, R., Nitz, K., and Rowe, D. C. (1990). Behavior genetics and aggressive behavior in childhood. In Lewis, M., and Miller, S., (eds.), Handbook of Developmental Psychopathology, Plenum, New York, pp. 119-133.

Rowe, D. C. (1983). Biometrical genetic models of self-reported delinquent behavior: A twin study. Behav. Genet. 13: $473-490$.

Rutter, M. (1991). Nature, nurture and psychopathology: A new look at an old topic. Dev. Psychopathol. 3:125-136.

Rutter, M., and Redshaw, J. (1991b). Annotation: Growing up as a twin: Twin-singleton differences in psychological development. J Child Psychol. Psychiatr. 32:885-895.

Rutter, M., Tizard, J., and Whitmore, K. (1970). Education, Health, and Behaviour, Longman, London (reprinted Krieger, Melbourne, 1981).

Rutter, M., Bolton, P., Harrington, R., Le Couteur, A., Macdonald, H., and Simonoff, E. (1990a). Genetic factors in child psychiatric disorders-I. A review of research strategies. J. Child Psychol. Psychiat. 31:3-37.

Rutter, M., Macdonald, H., Le Couteur, A., Harrington, R., Bolton, P., and Bailey, A. (1990b). Genetic factors in child psychiatric disorders-II. Empirical findings. $J$. Child Psychol. Psychiat. 31:39-83.

Scarr, S. (1966). Genetic factors in activity motivation. Child Dev. 37:663-673.

Shields, J. (1977). Polygenic influences. In Rutter, M., and Hersoy, L. (eds.), Child and Adolescent Psychiatry: Modem Approaches, Blackwell Scientific, Oxford, pp. 2246.

Stevenson, J., Batten, N., and Cherner, M. (1992). Fears and fearfulness in children and adolescents: A genetic analysis of twin data. J. Child Psychol. Psychiat. 33:977-986.

Tizard, B. (1977). Adoption: A Second Chance, Open Books, London.

Torgersen, A. M. (1982). Influence of genetic factors on temperament development in early childhood. In Temperamental Differences in Infants and Young Children, Ciba Foundation Symposium 89, Pitman, London, pp. 141154.

Van den Oord, E. J. C. G. (1993). A Genetic Study of Problem Behaviors in Children, Unpublished doctoral dissertation.

Van Westerlaak, J. M., Kropman, J. A., and Collaris, J. W. M. (1975). Beroepenklapper [Index of occupations]. Instituut voor Toegepaste Sociologie, Nijmegen.

Verhulst, F. C., and Koot, H. M. (1992). Child Psychiatric Epidemiology: Concepts, Methods, and Findings. Developmental Clinical Psychology and Psychiatry, Vol. 23, Sage, Newbury Park.

Verhulst, F. C., Althaus, M., and Versiuis-den Bieman, H. J. M. (1990a). Problem behavior in international adoptees. I. An epidemiological study. J. Am. Acad. Child Adolesc. Psychiat. 29:94-103.

Verhulst, F. C., Althaus, M., and Versluis-den Bieman, H. J. M. (1990b). Problem behavior in international adoptees. II. Age at placement. J. Am. Acad. Child. Adolesc. Psychiat. 29:104-111.

Verhulst, F. C., Versluis-den Bieman, H. J. M., Van Der Ende, J., Berden, G. F. M. G., and Sanders-Woudstra, J. A. R. (1990c). Problem behavior in international adoptees. III. Diagnosis and child psychiatric disorders. I. Am. Acad. Child Adolesc. Psychiat. 29:420-428.

Verhulst, F. C., Althaus, M., and Versluis-den Bieman, H. J. M. (1992). Damaging backgrounds. Later adjustment of international adoptees. J. Am. Acad. Child Adolesc. Psychiat. 31:518-525.

Wierzbicki, M. (1987). Similarity of monozygotic and dizygotic child twins in level and lability of subclinically depressed mood. Am. J. Orthopsychiat. 57:33-40.

Willerman, L. (1973). Activity level and hyperactivity in twins. Child Dev. 44:288-293.

Edited by N. G. Martin 